\title{
Development and construction of a conical solar concentrator
}

\author{
Ike, C. U. \\ Department of Physics/Ind. Physics Nnamdi Azikiwe University, Awka, Nigeria \\ E-mail:nelikechin@yahoo.com
}

Copyright $\odot 2014$ Ike, C. U. This is an open access article distributed under the Creative Commons Attribution License, which permits unrestricted use, distribution, and reproduction in any medium, provided the original work is properly cited.

\begin{abstract}
This research work reports the development, construction and study of the performance of the conical shaped concentrator made from fabricated iron sheet of thickness $2 \mathrm{~mm}$. The inner side of the cone shape was line with strips of plane mirror cemented to the surface by the help of araldite mixed with sawdust. The concentrator has an aperture of $8050.20 \mathrm{~cm} 2$ while the two solar absorber used for the study has surface area $790.60 \mathrm{~cm} 2$ and $720.50 \mathrm{~cm} 2$ with the concentration ratio being 9.50 and 10.60 respectively. The conical solar concentrator was tested under various operation condition, such as; different concentration ratio, static condition of the absorber fluid temperature against local time of the day showed that higher temperatures of the fluid were obtained on bright sunny days when the collector received beam radiation (highest temperature recorded $=166 \mathrm{oC}$ ) and a rapid decline of the fluids temperatures when a cloudy interception of the sun occurred.
\end{abstract}

Keywords: Aperture; Concentration Ratio; Solar Absorber; Solar Contractor; Working Fluid.

\section{Introduction}

Fossil fuel coal, gas, and oil still remain the conventional source of energy utilized by man for domestic and industrial uses. These sources of energy came indirectly from the sun in that they were formed some thousands of years ago from decayed plants and animals that once depended on the sun for life and growth. Generally, these fossil fuels may be thought of as "stored" solar energy.

However, the energy crisis which recently resulted from high energy demand coupled with rising cost of crude oil which accounted for the largest convectional energy source, has led to a considerable interest in solar energy for additional source of energy in highly industrialized and some developing countries. This same energy crisis has prompted research growth in the area of sun. Its radiations and possibilities of obtaining energy from it by employing different types of sun collecting system and methods of orientation and designing these collectors for maximum trappings of sun's energy for domestic and industrial uses [1].

The amount of energy radiated from the sun annually is estimated at $54 \times 10^{24}$ Joule per year, which is equivalent to at least 1000 times the amount of energy used presently in the whole world for the same period of time. The annual total horizontal solar radiation in Nigeria as determined from mean annual sunshine hours varies from $4500 \mathrm{MJ} / \mathrm{m}^{2}$ in the humid Niger Delta to over $9500 \mathrm{MJ} / \mathrm{m}^{2}$ in the far North-East Nigeria. This solar energy is transmitted through space to the earth by means of electromagnetic radiation in form of heat and high energy at a relatively low intensity. In various ways and capacities researchers have shown considerable interest in the sun and have employed different methods of harnessing its energy for domestic purposes such as solar cooking, water pumping and drying of food items in rural areas. Hence, solar concentrator is the device which utilizes the incident flux by concentrating it on a definite energy absorbing material for trapping heat energy [2].

There exists very many types of focusing collector each having different approaches in design and each being an improvement on the former. These include rotator parabolic mirror, cylindrical parabolic mirror, spherical mirror, cone mirror and Fresnel mirror. Of all these focusing collectors here mentioned, the conical solar concentrator was chosen for this research work based on

i) The geometry of design is less complex than other solar concentrators; 
ii) The energy received by the absorber is greater than any other concentrator/focusing collector of equal aperture area;

iii) Availability of local materials and relatively lower labour cost needed for the construction of the concentrator.

The development and construction of the conical concentrator with locally available materials are presented in the following subsections.

\section{Theoretical background}

Solar concentrators are types of focusing collectors which utilize optical system reflectors like mirrors or refractors like lenses to increase the intensity of solar radiation on an energy absorbing surface for applications requiring high temperatures such as is required for refrigeration, power generation and space heating. In focusing collectors, the reflecting and refracting surfaces are used to channel natural concentration of solar energy falling on an area into a significantly smaller area i.e. the focus of the system. Thus the energy intensity at the focus is much greater than that of the natural sunlight as shown in fig. 1. The area that receives this augmented insolation is called the "hot spot" and may be a small circle, a rectangle, a thin wire or cylindrical shape, depending on the techniques used [3]. The concentration ratio, $\mathrm{C}$, is defined as the extent to which concentration is achieved and is generally expressed as the ratio of effective aperture area Aa, to the area of the solar energy absorber, Ar.

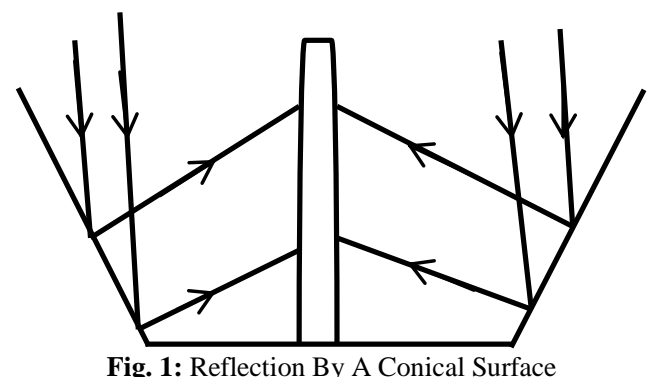

The concentration ratio is an important factor in determining the amount of heat intercepted by the solar absorber [4]. As $\mathrm{C}$ increases the heat loss per aperture decreases. At optimal concentration ratio an incremental heat loss equal the incremental loss of intercepted solar radiation. However, most of these concentrators have certain essential features in common, these are

i) Reflecting or refracting surface

ii) Absorbing surface and fluid

iii) Tracking system

iv) Storage system

Reflectors that are surface of revolution generally must be oriented so that the focus vertex and the sun are in the (position whereby no shadow of the absorber is cast on the wooden base of the collector). The solar collector delivers a constant flow of heat by tracking the sun as it moves across the sky so that the collector must be able to move about two axes. These axes may for example be horizontal and vertical or one axis of rotation may be inclined so that it is parallel to the earth's axis of rotation (i.e. polar axis) and the other perpendicular to it [5].

\section{Design and concentration of the conical concentrator}

Essentially, the collector is a frustum of a right circular cone (slant angle $=45^{\circ}$ ) upper circular diameter $=102 \mathrm{~cm}$ and lower circular diameter equal to $20.7 \mathrm{~cm}$. The slant height of the frustum is $57.6 \mathrm{~cm}$ while the vertical height is $40.7 \mathrm{~cm}$. The frustum was rolled into shape as shown in fig. 2 using iron sheet of $2 \mathrm{~mm}$ thickness and braced at the adjoining ends of welding.

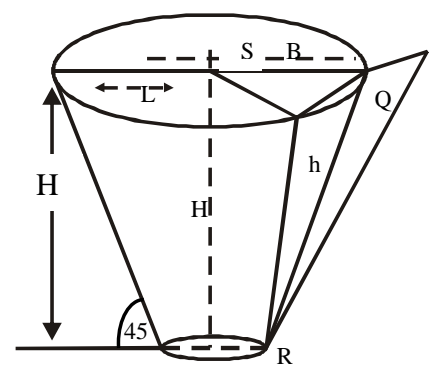

Fig. 2: Frustum of A Right-Circular Cone. 
The iron rods $\mathrm{P}$ and $\mathrm{Q}$ made of mild steel of length $30 \mathrm{~cm}$ and diameter $1.5 \mathrm{~cm}$ each were welded to the sides of the cone along an axis passing through its centre of gravity.

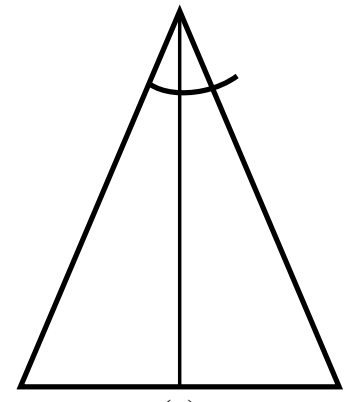

(a)

Fig. 3: Sections of Lower and Upper Polygon

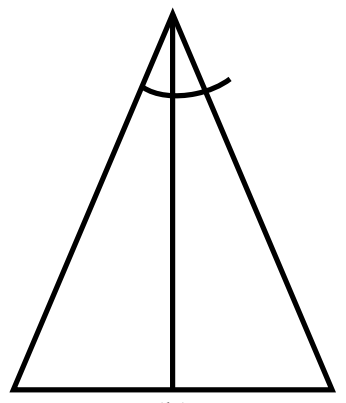

(b)

These two rods were joined through the centre of the collector to rectangular frame in such a way that the rods P and Q will have free axis of rotation along RS direction. They were bracketed to the frame using a bolts and nuts arrangement to allow North-South direction and also to ensure for a fixed position for trapping of the sun energy. The rectangular frame upon which the conical collector rests is made of an angle iron on the sides of which two mild steel rods $\mathrm{R}$ and $\mathrm{S}$ of length $30 \mathrm{~cm}$ and diameter $1.5 \mathrm{~cm}$ are welded. These two rests the entire weight of the angle iron frame and the conical collector on the wooden planks A and B which act as the main support, thus enabling the collector to track the sun along East-West direction. Two scales for measuring the angle of inclinations of the sun to the horizontal along the North-South direction and East-West direction were attached to rod $\mathrm{R}$ and plank A respectively.

\subsection{Reflecting surface}

The reflecting surface of the collector is made of finite numbers of mirror strips gummed to the inner surface of the collector using araldite mixed with sawdust to ensure it properly sticked to the surface. The mirror strips each has an upper and lower width equal to $5 \mathrm{~cm}$ and $1 \mathrm{~cm}$ respectively and length equal to the slant height of the conical collector which is $57 \mathrm{~cm}$. The upper and lower width form a regular polygon of sixty-four sides each of which constitutes the base side of sixty-four isosceles triangles of fig. 3 forming both the upper and lower aperture of the conical collector. A total of 64 mirror strips were used for the reflecting surface [6].

\subsection{The absorbing surface}

The absorber is a tubular structure made from a copper sheet. The copper sheet was rolled into a cylindrical form, and then braced at the adjoining end by a zinc metal alloy, it is then painted with a black body absorber. Two copper pipes of length $52.7 \mathrm{~cm}$ and $12.2 \mathrm{~cm}$ and having equal diameter serves as the inlet and outlet fluid flow sources respectively as shown in fig. 4.

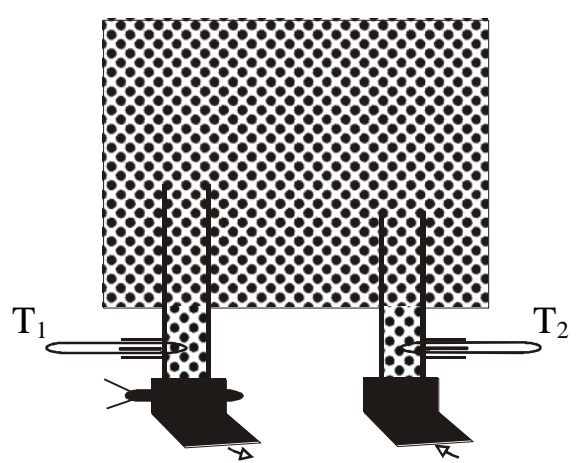

Fig. 4: Cross Sectional View of Solar Concentrator Absorber

Thermometer junctions were attached to each of the pipes using a mixture of araldite and sawdust through which the inlet and outlet temperatures were measured [7].

\section{Experimental procedures and measurements}

The working fluid used in the absorber for the research work was a black engine oil of low specific heat capacity, with a high boiling point temperature. Here, two perpendicular axes of rotation were adopted with continuous adjustment by 
hand, such that, the sun image is constantly reflected to the absorber. The hourly orientation of the concentrator is along a given axis. A semi-circular scale attached to the wooden stand at a pivoted position gives the angle of inclination of the sun to the horizontal in its daily motion in East-West direction. It was observed that the inclination of the sun to the horizontal maintains a value of $15^{\circ}$ in one hour. Another axis of orientation of the concentrator is the North-South direction, meant for tracking of the sun in its seasonal movement. A circular scale is also attached to the frame to measure the inclination of the sun to the horizontal along this axis.

The experimental recordings of the sun energy trapped by the absorber took a total of seven days, with the recordings starting from 9.30am and ending at 5.30pm and each of the days at an interval of 30minutes except on days 5 and 7 as shown in Tables 3 and 4. Days 1 to 4 recordings were taken with both inlet and outlet fluid flow sources closed. Another third thermometer was inserted through a hole punched at the flat end of the absorber to measure the temperature $\mathrm{T}_{3}{ }^{\circ} \mathrm{C}$ of the working fluid. On days 5,6 and 7 observations were recorded with the different flow rate of the working fluid.

\section{Results and discussions}

A summary of the measurement for all the days on which these readings were recorded shows that higher working fluid temperatures were obtained on sunny day when the collector received full beam radiation (highest temperature recorded was $166^{\circ} \mathrm{C}$ ) [8]. This can be observed from Tables 1 to 4 and from the graphs of figs. 5 and 6 . A rapid decline in working fluid temperatures occurred when there were cloudy interceptions of the sun. Two solar absorbers used for the observation have concentration ratios $\mathrm{Cr},=10.96$ and $\mathrm{Cr}_{2}=9.82$. The highest temperature of $166^{\circ} \mathrm{C}$ was obtained with the absorber with higher concentration ratio $(\mathrm{Cr}=10.96)$ on the $4^{\text {th }}$ day of the recording at $1.30 \mathrm{pm}$.

Table 1: Temperature of the Absorber Working Fluid Against Local Time of the Day For Static Condition of the Working Fluid For Day 1 and Day 2

\begin{tabular}{|c|c|c|c|c|c|}
\hline \multicolumn{3}{|c|}{ Day 1} & \multicolumn{3}{|c|}{ Day 2} \\
\hline Local time of the day & $\mathrm{Ta}^{\circ} \mathrm{C}$ & $\mathrm{Ts}^{\circ} \mathrm{C}$ & Local time of the day & $\mathrm{Ta}^{\circ} \mathrm{C}$ & $\mathrm{Ts}^{\circ} \mathrm{C}$ \\
\hline 9.30am & 28.40 & 78.00 & $10.00 \mathrm{am}$ & 27.5 & 74.0 \\
\hline $10.00 \mathrm{am}$ & 28.60 & 110.00 & $10.30 \mathrm{am}$ & 28.0 & 90.0 \\
\hline $11.30 \mathrm{am}$ & 30.00 & 125.00 & $11.00 \mathrm{am}$ & 28.4 & 122.0 \\
\hline 11.00am & 30.20 & 128.00 & 11.30am & 28.8 & 120.0 \\
\hline 11.30am & 32.40 & 122.00 & 12.00am & 30.0 & 108.0 \\
\hline 12.00noon & 32.20 & 120.00 & $12.30 \mathrm{pm}$ & 30.1 & 134.0 \\
\hline $12.30 \mathrm{pm}$ & 32.50 & 110.00 & $1.00 \mathrm{pm}$ & 30.6 & 150.0 \\
\hline $1.00 \mathrm{pm}$ & 33.50 & 98.00 & $1.30 \mathrm{pm}$ & 31.1 & 148.0 \\
\hline $1.30 \mathrm{pm}$ & 33.00 & 90.00 & $2.00 \mathrm{pm}$ & 32.0 & 158.0 \\
\hline $2.00 \mathrm{pm}$ & 33.10 & 92.00 & $2.30 \mathrm{pm}$ & 32.7 & 134.0 \\
\hline $3.00 \mathrm{pm}$ & 33.00 & 62.00 & $3.30 \mathrm{pm}$ & 33.0 & 156.0 \\
\hline $3.30 \mathrm{pm}$ & 33.20 & 62.00 & $4.00 \mathrm{pm}$ & 33.3 & 120.0 \\
\hline $4.00 \mathrm{pm}$ & 33.60 & 62.00 & $4.30 \mathrm{pm}$ & 33.5 & 80.0 \\
\hline $4.30 \mathrm{pm}$ & 33.60 & 62.00 & $5.00 \mathrm{pm}$ & 33.7 & 82.0 \\
\hline $5.00 \mathrm{pm}$ & 33.60 & 94.00 & & & \\
\hline $5.30 \mathrm{pm}$ & 33.60 & 62.0 & & & \\
\hline
\end{tabular}

Table 2: Temperatures of the Absorber Working Fluid against Local Time of the Day for Non-Static Condition of the Working Fluid for Day 5.

\begin{tabular}{|c|c|c|c|c|c|c|c|}
\hline $\begin{array}{l}\text { Local time of } \\
\text { the day }\end{array}$ & $\mathrm{Ta}^{\circ} \mathrm{C}$ & $\mathrm{T}_{1}{ }^{\circ} \mathrm{C}$ & $\mathrm{T}_{2}{ }^{\mathrm{o}} \mathrm{C}$ & $\begin{array}{l}\text { Estimated value of solar } \\
\text { Radiation } \mathrm{HbR}_{\mathrm{b}}\left(\mathrm{WHR} / \mathrm{m}^{2}\right) \\
\text { Received Half/Hour }\end{array}$ & $\begin{array}{l}\text { Heat energy } \\
\text { gained by the } \\
\text { collector (WHR) }\end{array}$ & $\begin{array}{l}\text { Efficiency of } \\
\text { collector }\end{array}$ & $\begin{array}{l}\text { Percentage } \\
\text { Efficiency of the } \\
\text { Collector } \%\end{array}$ \\
\hline $9.00 \mathrm{am}$ & 25.4 & 30.0 & 68.0 & 1400 & 760.08 & 0.667 & 66.7 \\
\hline $9.30 \mathrm{am}$ & 26.8 & 33.0 & 80.0 & 1400 & 765.03 & 0.662 & 66.2 \\
\hline 10.00am & 27.8 & 35.0 & 90.0 & 1700 & 917.06 & 0.663 & 66.3 \\
\hline 10.30am & 28.0 & 38.0 & 98.0 & 1900 & 1023.99 & 0.662 & 66.2 \\
\hline 11.00am & 28.6 & 38.0 & 80.0 & 2000 & 1087.80 & 0.668 & 66.8 \\
\hline $11.30 \mathrm{am}$ & 29.3 & 40.0 & 78.0 & 2000 & 1078.70 & 0.669 & 66.9 \\
\hline $12.00 \mathrm{am}$ & 29.9 & 40.0 & 80.0 & 1900 & 988.69 & 0.639 & 63.9 \\
\hline $12.30 \mathrm{pm}$ & 30.6 & 39.0 & 85.0 & 1300 & 697.36 & 0.659 & 65.9 \\
\hline $1.00 \mathrm{pm}$ & 31.1 & 38.0 & 52.0 & 1200 & 655.90 & 0.671 & 67.1 \\
\hline $\begin{array}{l}\text { Working fluid } \mathrm{r} \\
\mathrm{M}_{1}-1.3086 \mathrm{~g} / \mathrm{s} ; \\
\mathrm{T}_{\mathrm{a}}{ }^{\circ} \mathrm{C}-\text { ambient } \\
\mathrm{T}_{1}{ }^{\circ} \mathrm{C}-\text { inlet tem } \\
\mathrm{T}_{2}^{\circ} \mathrm{C}-\text { outlet ter }\end{array}$ & $\begin{array}{l}\text { te of flo } \\
\text { FR }_{1}-0 \\
\text { emperat } \\
\text { gerature } \\
\text { iperatur }\end{array}$ & $\begin{array}{l}-1.5 \mathrm{c} \\
909275 \\
\mathrm{e}\end{array}$ & & & & & \\
\hline
\end{tabular}




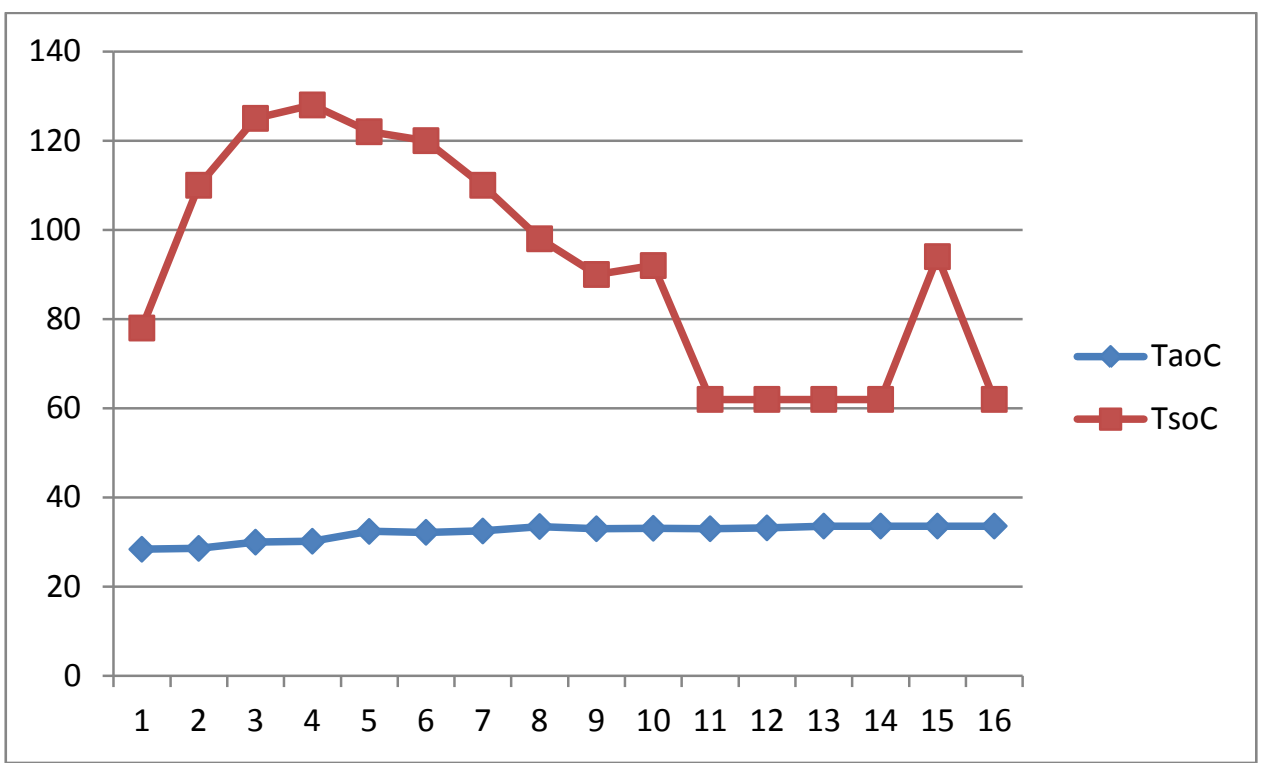

For day 1
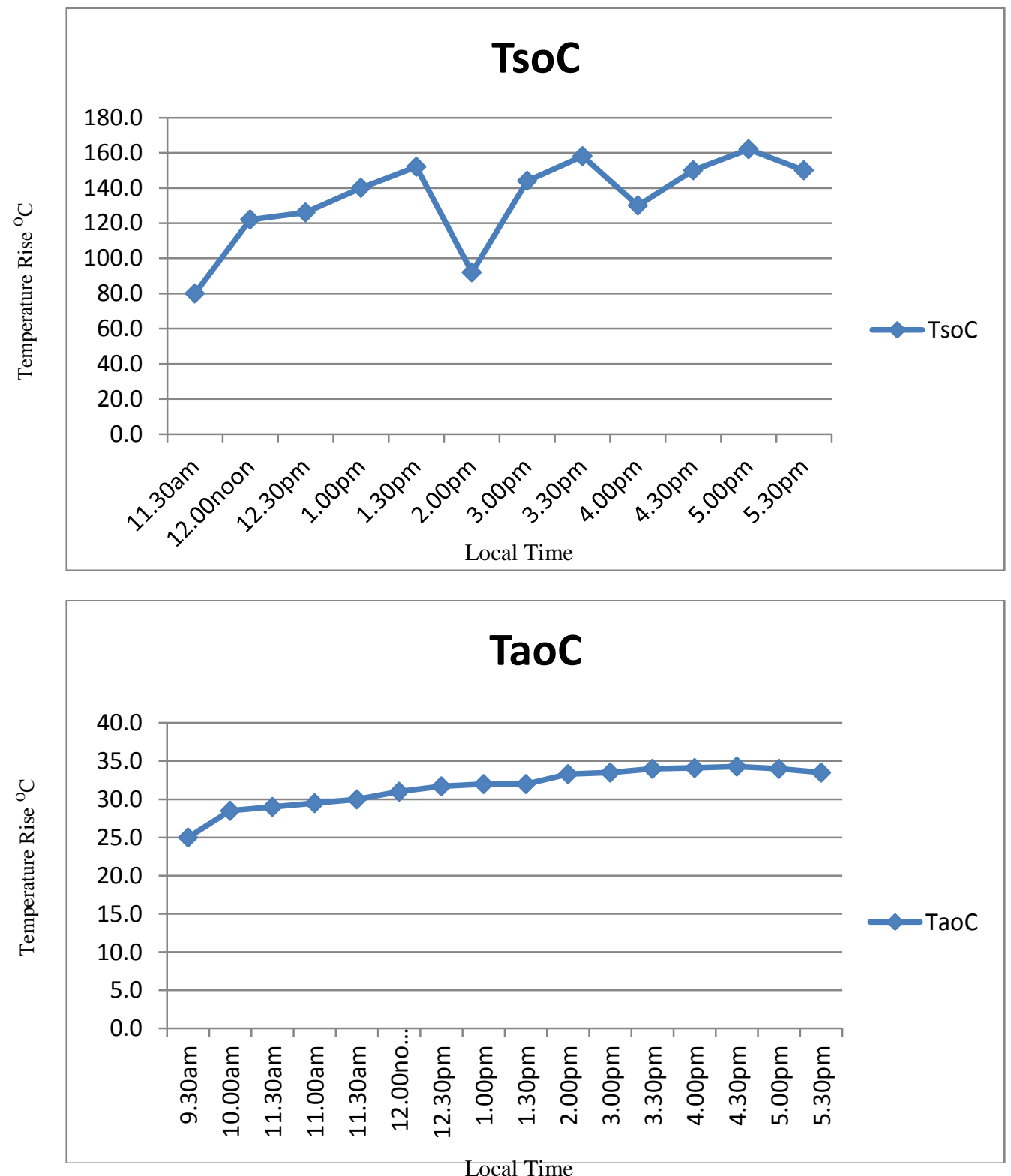


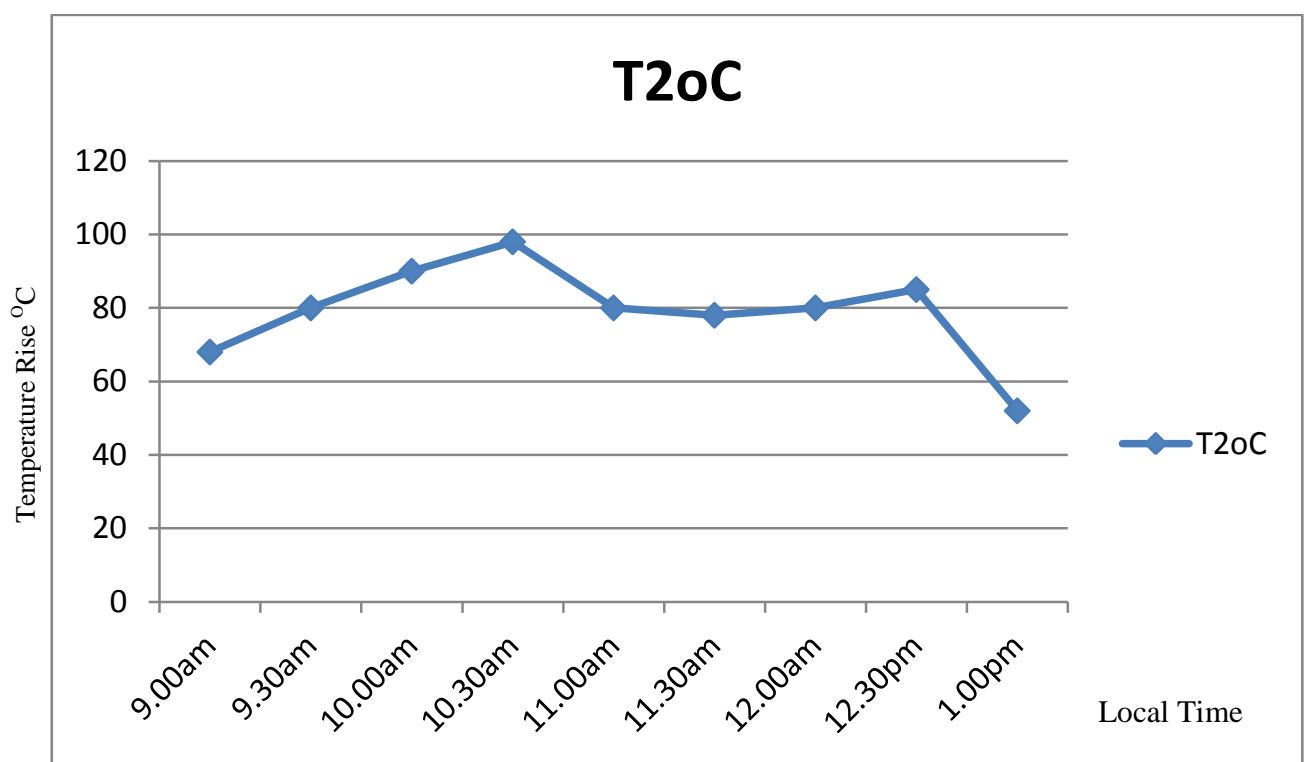

Fig. 5: Graphs of Working Fluid Temperature (Static Condition) Against Local Time of the Day Days 1, 3, 4 and 5.
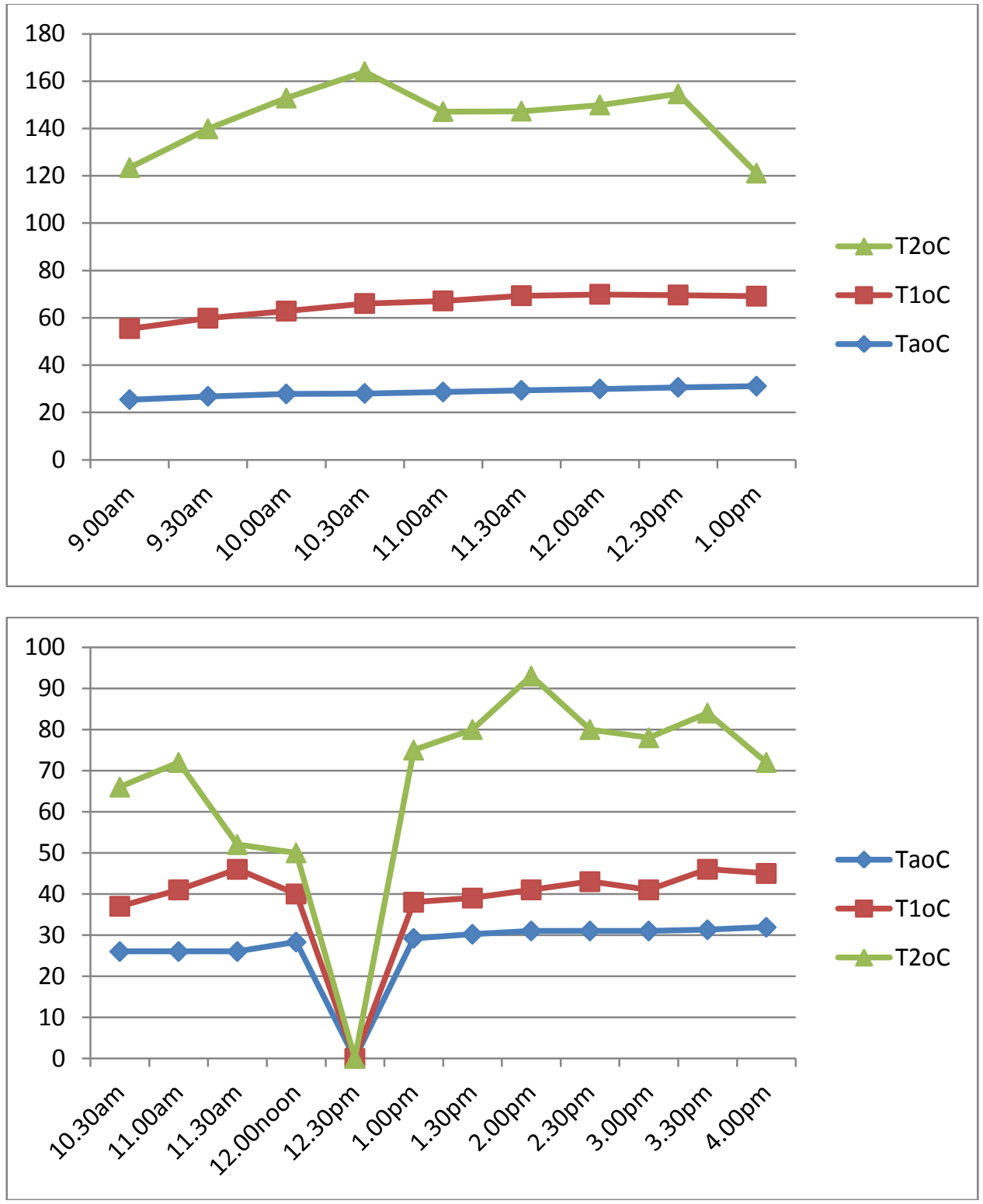


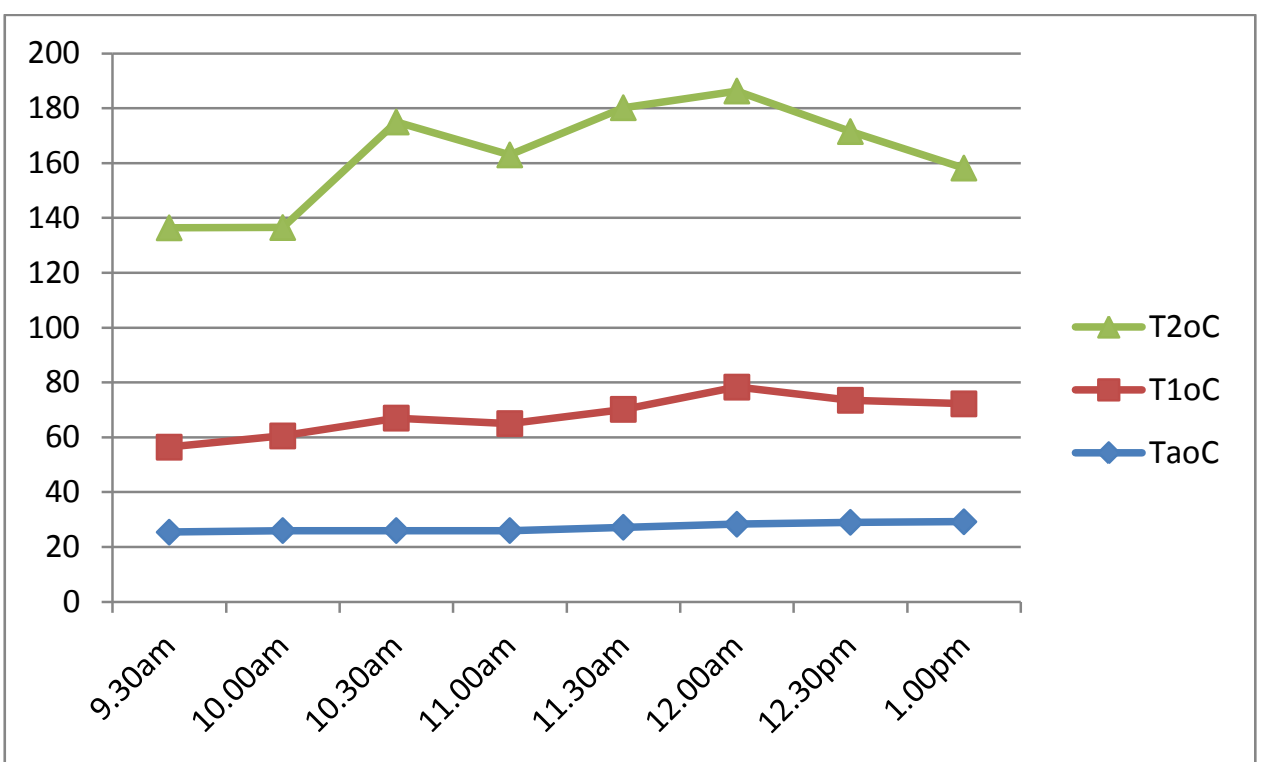

Fig. 6: Graphs of Working Fluid Temperature (Different Rate of Flow) Against Local Time of the Day for Days 5, 6 and 7.

\section{Conclusion}

The thermal efficiency and overall heat energy gained by the solar concentrator calculated using Hottel-whillier-Bliss equation for non-static conditions of the working fluid shows that the solar concentrator, when equipped with a receiver of high concentration ratio can be used to achieve a high temperature applications such as refrigeration and air conditioning purposes, where high temperature of the working fluid is required. Also concentrator with wider aperture area, equipped with electronic sun tracking devices for constant trapping of sun energy can be used to heat water to generate steam to drive turbine, in generating electricity.

\section{References}

[1] E. B. Babatunde, Some solar radiations and their interpretations with regards to radiations and their interpretations with regards to radiation transfer in the atmosphere. Nigerian Journal of Pure and Applied Science, (2003), 4; 50 - 56

[2] E. A. Arinze, Solar energy for crop drying in developing countries proceedings of workshop on solar drying in Africa, Dakar Senegal, (1986), 128-147

[3] D. A. Adeyemo, B. S. Allimi, D. A. Pelemo, M. K. Fasasi, S. A. Owolabi, and J. A. Shaniyi, Design, Construction and Performance of focusing type solar cooker (Nig.), Journal of Physics (2002), 14(2), 109 - 112.

[4] C. U. Ike, Climatological effects of total solar radiation in Awka, Nigeria, IOSR Journal of Applied Physics, (2013), 5(2), 51-54

[5] R. T. A. Prodo, and F. L Ferreira,. Management of albedo and analysis of its influence on the surface temperature of building materials. (2005),

[6] E. B. Babatunde, A. O. Falaiye, and A. B. Afolabi, Solar radiation energy balancing at the edge of the earth's atmosphere. Proc. of regional conference on climate change of Nigeria Meteorological Society (NMS), Lagos, Nigeria, (2003), 11-14 November.

[7] C. U. Ike, The effect of temperature on the performance of a PV solar system in Eastern Nigeria, International Journal of Engineering and Science, (2013), Vol. 3, $10-14$

[8] A. Shariah, and G. Lof, Effects of auxiliary heater on annual performance of thermosyphon solar water heater simulated under variable operating conditions, solar energy 2009, (2010), 60, 119-126. 